\title{
Crença de autoeficácia e identidade profissional: Estudo com professores do ensino médio
}

\author{
Belief in self-effectiveness and professional identity: a study with high school teachers
}

Leticia Benvenuti Castelo ${ }^{[a]}$, lúri Novaes Luna ${ }^{[b]}$

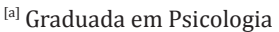
pela Universidade Federal de Santa Catarina (UFSC), Florianópolis, SC - Brasil, e-mail: leticiacastelo@gmail.com

${ }^{[b]}$ Doutor em Sociologia Política pela Universidade Federal de Santa Catarina (UFSC), professor do curso de Mestrado em Administração e do curso de Psicologia da Universidade do Sul de Santa Catarina (UNISUL), Florianópolis, SC - Brasil, e-mail: iuri.luna@unisul.br
}

Recebido: 22/07/2011 Received: 07/22/2011

Aprovado: $18 / 10 / 2011$ Approved: 10/18/2011

\section{Resumo}

A investigação visa contribuir para a compreensão da categoria profissional dos professores mediante a identificação da relação, ainda pouco explorada na literatura, entre a crença de autoeficácia e a identidade profissional. A autoeficácia refere-se à crença da pessoa sobre sua capacidade para exercer determinada atividade, enquanto que a identidade profissional é entendida como o resultado das percepções da pessoa a respeito de si mesma e dos outros sobre ela, em seus aspectos profissionais. Foi realizado um levantamento, por meio de uma escala de autoeficácia docente, com professores do ensino médio de duas escolas brasileiras, uma pública e uma privada. Posteriormente foram efetuadas entrevistas com oito professores, os dois com maior e os dois com menor crença de autoeficácia de cada escola. Mediante a análise de conteúdo, as informações coletadas foram sistematizadas com base nos dois constructos centrais do trabalho. Não obstante os resultados da escala, os oito professores se identificam com sua profissão e se percebem capazes de ensinar. Destarte, a crença de autoeficácia aparece como um fator significativo no processo de construção da identidade profissional de professores.

Palavras-chave: Identidade profissional. Autoeficácia. Professores.

\section{Abstract}

This research aims to contribute for the understanding of the profession of teachers by identifying the relationship, yet little explored in the literature, among the belief in self-efficiency and professional identity. The self-efficiency refers to a person's belief about her ability to exercise certain activity, while the professional identity is understood as the result of the perceptions a person has about herself and others aroud her, in its professional aspects. A research was performed about teacher self-efficiency scale with secondary school teachers from a public school and a private school in Brazil. Subsequent interviews were conducted with eight teachers, two with the grestest belief in self-efficiency and two with the lowest belief in self-efficiency from each school. The collected information was systematized by content analysis based on the two central constructs researched. Notwithstanding the results of the scale, all eight professors 
identified with their profession and noticed themselves as capable to teach. Thus, the belief in self-efficiency appears as a significant factor in the construction of professional identity for teachers.

Keyword: Professional identity. Self-efficiency. Teachers.

\section{Introdução}

Considerando a relevância da prática docente para o desenvolvimento socioeconômico dos países, bem como o impacto da atividade profissional sobre a subjetividade dos professores, o presente estudo apresenta os conceitos de autoeficácia e identidade profissional, para articulá-los mediante uma investigação científica junto a professores do ensino médio. De maneira sucinta, o fenômeno da autoeficácia diz respeito à crença do sujeito com relação a sua capacidade de realizar com sucesso determinada atividade, enquanto que a identidade profissional é entendida, de forma genérica, como resultado do movimento das percepções da pessoa sobre si mesma e dos outros sobre ela, em sua dimensão profissional.

A discussão acerca do constructo da autoeficácia iniciou em 1977, quando o psicólogo Albert Bandura apresentou em seu artigo Self-efficacy: Toward a Unifying Theory of Behavioral Change a então chamada expectativa de eficácia, diferenciando-a da expectativa de resultado. A primeira diz respeito à convicção de alguém quanto a realizar determinada atividade com sucesso e produzir o resultado esperado, enquanto que a segunda refere-se à estimativa de uma pessoa de que um dado comportamento irá produzir determinado resultado. Dessa forma, uma pessoa pode estimar qual comportamento produzirá o resultado esperado, no entanto, se a pessoa não acreditar que é capaz de realizar com sucesso tal atividade, essa estimativa não influenciará seu comportamento (Bandura, 1977).

A Teoria da Autoeficácia veio como complemento à teoria da aprendizagem social, proposta por Bandura e Walters em 1963. Em 1977, Bandura identificou que faltava um elemento fundamental em sua teoria: "que os indivíduos criam e desenvolvem percepções pessoais sobre si mesmos, as quais se tornam instrumentais para os objetivos que perseguem e para o controle que exercem sobre seu próprio ambiente" (Pajares \& Olaz, 2008, p. 97). A Teoria da Aprendizagem Social foi intitulada por Bandura, em 1986, como Teoria Social Cognitiva, por demonstrar o papel central dos processos cognitivos na forma como as pessoas constroem sua realidade, se autorregulam, codificam informações e executam comportamentos.

As crenças de autoeficácia, enquanto percepções que as pessoas têm acerca de suas capacidades em determinadas atividades, localizam-se no núcleo da Teoria Social Cognitiva e são a base para as realizações pessoais, para a motivação humana e para o bem-estar. Observa-se que de acordo com Bandura (1977), os estados afetivos, a motivação e as ações das pessoas são baseadas principalmente no que elas acreditam e não no que é objetivamente verdadeiro. Assim sendo, as pessoas desenvolvem suas crenças de autoeficácia por meio da interpretação de quatro fontes: experiência direta, experiência vicária, persuasões sociais e estados somáticos e emocionais. A fonte mais influente é a experiência direta por se tratar da interpretação do resultado de um comportamento pessoal anterior (Pajares \& Olaz, 2008).

Além do processo cognitivo envolvido na interpretação dos resultados de seus próprios atos, as pessoas criam suas crenças de autoeficácia por meio da interpretação da experiência vicária, ou seja, a partir da observação de outras pessoas, com características semelhantes as suas, executando tarefas. Os indivíduos ainda desenvolvem crenças de autoeficácia em razão das persuasões sociais, que envolvem a exposição a julgamentos verbais de outrem, bem como do seu estado emocional e fisiológico, uma vez que o estresse, a excitação, a ansiedade e os estados de humor podem ser levados em consideração quando a pessoa avalia suas crenças (Pajares \& Olaz, 2008). Enfim, cabe acrescentar que as fontes das crenças de autoeficácia raramente operam 
separadamente (Nunes, 2008) e que as crenças dependem da interpretação que as pessoas fazem de cada uma das quatro fontes (Bandura, 1994). Dessa forma, não se trata de uma relação causal ou linear entre as fontes e a autoeficácia, mas sim de uma relação mediada pela interpretação e pelo entendimento elaborados pelo sujeito.

No que se refere ao conceito de identidade, observa-se a existência de diversas linhas de pensamento, oriundas de diferentes áreas do conhecimento e referenciais teóricos, tais como da própria sociologia (Dubar, 1998; Sader, 1988), dos estudos culturais (Guareschi, Medeiros \& Bruschi, 2003; Hall, 2001; Silva, 2004; Woodward, 2004) e da psicologia social (Ciampa, 2007; Coutinho, 1999; Jacques, 1996; Luna \& Baptista, 2001; Martin-Baró, 1985). Não obstante suas diferenças no que se refere à possibilidade do sujeito manter uma relativa unidade no decorrer de sua trajetória identitária, tais abordagens possuem em comum, além da investigação dos processos identitários construídos no cotidiano, "a ênfase na dinâmica e na processualidade, a interdependência indivíduo e coletivo, a análise da alterização e da indissociabilidade entre identidade e diferença, a recusa da essencialidade e da soberania do sujeito". (Coutinho, Krawulski \& Soares, 2007, p. 31). A psicanálise, por sua vez, também contribui para o debate, na medida em que discute as identidades e os processos identificatórios inconscientes (Costa, 1989; Erikson, 1976).

Tendo como referência o pensamento de autores associados à psicologia social, para se conhecer a identidade de alguém, é preciso não apenas conhecer o que cada pessoa responde à pergunta "Quem é você?", mas também investigar como ela é percebida pelos demais que se encontram envolvidos em suas relações sociais. Trata-se, portanto, de um conceito que envolve tanto o autorreconhecimento como também o reconhecimento dos outros, ou seja, "não é uma simples imagem mental de mim-mesmo, pois ela se configurou na relação com outrem que também me identifica como idêntico a mim-mesmo" (Ciampa, 2007, p. 69). Desta forma, é fundamental considerar o contexto social e a historicidade em que a identidade foi e é construída a cada momento em um processo contínuo (Luna \& Baptista, 2001).

Em relação especificamente à identidade profissional, observa-se que essa dimensão ocupa um lugar de destaque no contínuo processo de construção da identidade pessoal, uma vez que é o trabalho que possibilita aos atores sociais a transformação de suas condições de existência, o que envolve condições objetivas e subjetivas: é na "práxis, que é a unidade da subjetividade e da objetividade, que o homem se produz a si mesmo e concretiza sua identidade. 0 devir humano é o homem ao se concretizar" (Ciampa, 1987, p. 201).

Em um estudo de caso apresentado por Santos e Santos (1993), as autoras apresentam, como componentes básicos que estruturam e mantêm a identidade, as experiências de reconhecimento, de valorização pessoal e de poder. Tais componentes podem ser pensados e correlacionados com a crença de autoeficácia, entendida como a percepção de alguém acerca de suas capacidades relacionadas a uma atividade específica - nesse caso, a atividade profissional. De acordo com as autoras, se o contexto profissional não permitir que a pessoa tenha as experiências de reconhecimento, de valorização pessoal e de poder, esta poderá investir na família como a única fonte de tais sentimentos para tentar se manter enquanto sujeito.

A identidade dos trabalhadores é construída tendo como base as relações que estabelecem com seu contexto social (Coutinho, 1999), o que foi evidenciado em uma pesquisa sobre a construção da identidade docente de alunas de um curso de Pedagogia, realizada mediante a História de Vida (Freitas, 2006). Sendo assim, associar a construção da identidade profissional com as crenças de autoeficácia possibilita identificar pontos em que os dois processos se cruzam, tendo em vista que a identidade profissional tem como uma de suas características principais a percepção que o sujeito tem de si mesmo e os sentidos que atribui às relações sociais.

Diversos estudos acerca das condições de trabalho dos docentes, bem como da precarização da profissão, podem ser encontrados na literatura, principalmente em virtude das modificações que vêm ocorrendo no mundo do trabalho e interferem no desenvolvimento de diversas profissões. De acordo com Oliveira (2004), em razão das variadas funções que a escola assume, o professor, muitas vezes, precisa responder a exigências que estão além de sua formação, o que pode resultar na defasagem da identidade profissional desses trabalhadores e em sentimentos de desprofissionalização, uma vez que a ação de ensinar perde o lugar central.

Um estudo realizado por Galindo (2004) demonstra um conflito vivenciado por professores do 
ensino fundamental do Recife. A partir do entendimento de identidade profissional como resultado, ou relação, entre o autorreconhecimento e o alterreconhecimento, a autora verificou, por meio de entrevistas com esses profissionais, que os professores se reconhecem e se identificam com as características da profissão docente. No entanto, de acordo com análise de material jornalístico sobre educação, professor e escola (o que é ser docente para a imprensa), os professores, muitas vezes, são relacionados a movimentos de greve, vistos como uma ameaça e responsabilizados por perdas sofridas pelos alunos e escolas, além de sua efetiva participação em programas de capacitação docente não ser destacada em matérias a respeito do assunto.

Ainda sobre a identidade profissional de docentes, uma investigação desenvolvida por Bragagnolo e Luna (2004) objetivou identificar como as novas exigências da Lei de Diretrizes e Bases da Educação (LDB 9.394/96, Brasil, 1996) relacionadas à atuação e formação profissional dos professores interferiram em sua identidade profissional. Destarte, além da identidade profissional dos professores estar enfraquecida em razão da flexibilização e precarização do trabalho docente (Oliveira, 2004), pode também ser impactada pela forma como os professores são vistos pela sociedade (Galindo, 2004) e pelo Estado (Bragagnolo \& Luna, 2004). Brando e Caldeira (2009) indicam ainda como cursos de licenciatura muitas vezes acentuam a construção da imagem do cientista pesquisador, no lugar de contribuir para a construção de uma identidade de professor de determinada área.

A identidade profissional, juntamente com outros fatores, interfere, ainda, no comprometimento dos profissionais com sua carreira. Esta relação pôde ser observada em um estudo realizado com profissionais de diferentes áreas, empregados em instituição de ensino superior, cujo objetivo principal era relacionar os processos de comprometimento, o entrincheiramento e a motivação vital em carreiras profissionais. A pesquisa demonstrou que a identidade com a carreira se relaciona com os custos emocionais de uma mudança (resiliência), enquanto que limitações de alternativas de carreira se relacionam inversamente com o planejamento para desenvolver e alcançar metas profissionais (Baiocchi \& Magalhães, 2004).

A presente investigação tenciona estudar a identidade profissional de professores mediante uma perspectiva ainda pouco explorada, ou seja, por meio de suas crenças de autoeficácia. Pesquisas sobre a autoeficácia de professores dos ensinos Fundamental e Médio demonstram a pertinência desta problemática. De acordo com Brophy (1991), nos anos 1960 e 1970, as pesquisas relacionadas às crenças de professores focavam aspectos mais genéricos do ensino. Relacionavam os ganhos dos alunos, por meio de testes de desempenho, com a maneira eficaz dos professores trabalharem em sala de aula. A partir de 1980, pôde-se perceber uma mudança de enfoque, principalmente graças aos métodos qualitativos que passaram a ser empregados: "A preocupação dos estudiosos voltou-se para os processos em sala de aula e a aprendizagem deveria ser medida com referência a critério". (Bzuneck, 1996, p. 2). Observa-se que não obstante o estudo da autoeficácia no contexto escolar também possa ser utilizado para a compreensão das estratégias de aprendizagem (Souza, 2010), este aspecto não será discutido, tendo em vista que a presente pesquisa tem como foco o professor, e não o processo de ensino e aprendizagem de forma ampla.

Bandura (1986) resume as consequências da crença de eficácia nos professores:

a) faz com que os professores estabeleçam metas para si próprio, busquem maiores desafios;

b) interfere no grau de esforço que os professores investirão nas tarefas;

c) interfere no grau de persistência, mesmo frente às dificuldades de percurso;

d) influi na forma como o professor reagirá frente aos fracassos eventuais da profissão.

Por meio da demonstração de diversos estudos realizados com professores acerca de sua crença de autoeficácia, Bzuneck (2000) demonstra as implicações desta para a prática educativa. De maneira geral, crenças elevadas de autoeficácia de professores estão relacionadas com um desempenho melhor dos alunos; refletem na autoeficácia dos alunos, o que interfere em sua motivação; faz com que o professor adote estratégias mais adequadas para atuar no processo de aprendizagem dos alunos. Em outra pesquisa, com professores de 1a a $4^{\mathrm{a}}$ séries, Bzuneck (1996) verificou que as professoras mais velhas e com mais tempo de trabalho apresentaram índices menores de crença de eficácia no ensino em geral, o que não aconteceu com os índices de crenças de autoeficácia. 
Nunes (2008) apresenta a importância de se estudar a autoeficácia para o trabalho do psicólogo em orientação profissional. A autora entende que a escolha profissional pode ser guiada, principalmente, pela acessibilidade das ocupações concretas, pela autoeficácia e pelas expectativas de resultados. Sendo os dois últimos fatores passíveis de intervenção, seu estudo é relevante para a atuação do psicólogo, pois possibilita:

a) observar em que atividades o sujeito apresenta fortes crenças de autoeficácia e expectativas de resultados;

b) intervir em baixos níveis de autoeficácia sobre atividades que a pessoa tem interesse, sobretudo quando estes estão relacionados a questões de gênero ou socioeconômicas.

Ainda sobre a relevância social do estudo, observa-se que um levantamento recente realizado pela Fundação Getúlio Vargas (2009), com base na análise dos microdados dos suplementos da Pesquisa Nacional por Amostra de Domicílios (Pnad), indicou como principal motivo da evasão escolar a "falta de interesse intrínseco". Dentre os fatores que compõem esta categoria, destaca-se, com $83,38 \%$ das respostas, a opção "não quis frequentar", que inclui problemas com professores. Ressalta-se, assim, a importância de pesquisas que possam contribuir para compreensão e posterior intervenção na prática docente.

Diante disso, na linha de investigação sobre a identidade profissional de docentes, este estudo visa compreender a relação entre a crença de autoeficácia de professores do ensino médio e sua identidade profissional, com a cautela de, ao utilizar conceitos pertencentes a teorias diversas, não ignorar as contradições entre seus pressupostos e relações (Alves-Mazzotti, 2002). Mais especificamente, pretende-se: identificar a crença de autoeficácia de professores do ensino médio no que se refere às suas atividades laborais; descrever o processo de desenvolvimento das crenças de autoeficácia dos professores; caracterizar a identidade profissional de professores do ensino médio.

\section{Método}

Trata-se de uma investigação predominantemente qualitativa, uma vez que se preocupa menos com a predição e o controle, do que com "a elucidação, o conhecimento dos complexos processos que constituem a subjetividade [...]" (González Rey, 2002, p. 48). Assim, busca compreender, sobretudo, os significados que os sujeitos atribuem aos fenômenos estudados. Sendo seu objetivo desenvolver conceitos e ideias, classifica-se como exploratória (Gil, 1999) e, quanto ao delineamento, como estudo de caso, por estudar unidades dentro de um sistema mais amplo, ao mesmo tempo similares a outras e distintas (Lüdke \& André, 1986). Diante de um contexto composto por múltiplas determinações, cada unidade, sendo singular, deve retratar a universalidade de uma situação. Sendo assim, este estudo apresenta subsídios para elucidar a relação entre a crença de autoeficácia docente e a identidade profissional de professores do ensino médio.

\section{Participantes}

Os participantes da pesquisa foram oito professores do ensino médio que trabalham em escolas da região da Grande Florianópolis, SC, e exercem a profissão docente há mais de cinco anos. Foram selecionados quatro professores de uma escola particular e quatro professores da rede pública de educação. 0 principal critério utilizado para seleção dos participantes foi o nível de autoeficácia. Em cada escola foram selecionados os dois professores com autoeficácia mais alta e os dois com autoeficácia mais baixa, desde que respeitado o critério relativo ao tempo de atuação como docente.

\section{Material e procedimentos}

Foram utilizadas duas técnicas de coleta de dados: uma escala de autoeficácia docente e uma entrevista semiestruturada. A escala de autoeficácia foi utilizada para a seleção dos professores participantes, na medida em que identificou o nível da crença de autoeficácia dos professores do ensino médio no que se refere às suas atividades laborais. Posteriormente, as informações dos professores selecionados foram obtidas mediante a técnica da entrevista, cujas questões foram elaboradas de acordo com os objetivos específicos da investigação.

Inicialmente foi aplicada a Escala de Autoeficácia Docente de Woolfolk e Hoy, adaptada para o contexto brasileiro e validada por Bzuneck e Guimarães (2003), em todos os professores das duas escolas escolhidas (particular e pública). A escala é composta 
por 20 afirmações relativas à prática docente, sendo que 12 delas mensuram a eficácia pessoal e as demais a eficácia no ensino em geral. Trata-se de uma escala do tipo likert de cinco pontos, desde total discordância $(1,0)$ até inteira concordância $(5,0)$. Observa-se que na presente investigação foram utilizados exclusivamente os resultados da eficácia pessoal, por ser o foco deste estudo.

As escalas de autoeficácia foram entregues aos professores acompanhado de um documento que solicitava dados de identificação e duas vias do Termo de Consentimento Livre e Esclarecido. Após o preenchimento, os participantes depositaram o material em envelopes individuais que, após lacrados, deveriam ser entregues a um responsável na escola. Na escola pública, dos 34 professores que receberam o material, 27 (79,41\%) o entregaram devidamente respondido. Na escola particular, 40 professores receberam o material e $20(50 \%)$ o devolveram, sendo que dois destes não puderam ser utilizados em decorrência do não preenchimento correto do Termo de Consentimento.

Com base nos resultados da Escala de Autoeficácia Docente, foram selecionados quatro professores de cada escola, os dois com resultados mais baixos de autoeficácia docente e os dois com resultados mais altos, para a realização da entrevista semiestruturada. Todas as entrevistas aconteceram nos respectivos colégios, nos horários em que os professores não estavam ministrando aulas. Foi esclarecido aos participantes que as identidades deles e do colégio seriam mantidas em sigilo; assim sendo, os nomes presentes na apresentação e discussão dos resultados são fictícios. Cada entrevista, com duração aproximada de 30 minutos, foi gravada e posteriormente transcrita.

\section{Análise dos dados}

Por se tratar de estudos de caso, a discussão dos resultados foi realizada por participante, mediante a análise de conteúdo. De acordo com Caregnato e Mutti (2006, p. 682), na análise de conteúdo "o texto é um meio de expressão do sujeito, em quem o analista busca categorizar as unidades de texto (palavras ou frases) que se repetem, inferindo uma expressão que as represente". As categorias de análise, elaboradas a posteriori, foram criadas tendo como base dois grandes focos: identidade profissional (IP) e autoeficácia. As Figuras 1 e 2 apresentam as categorias e subcategorias derivadas desses dois conceitos principais.

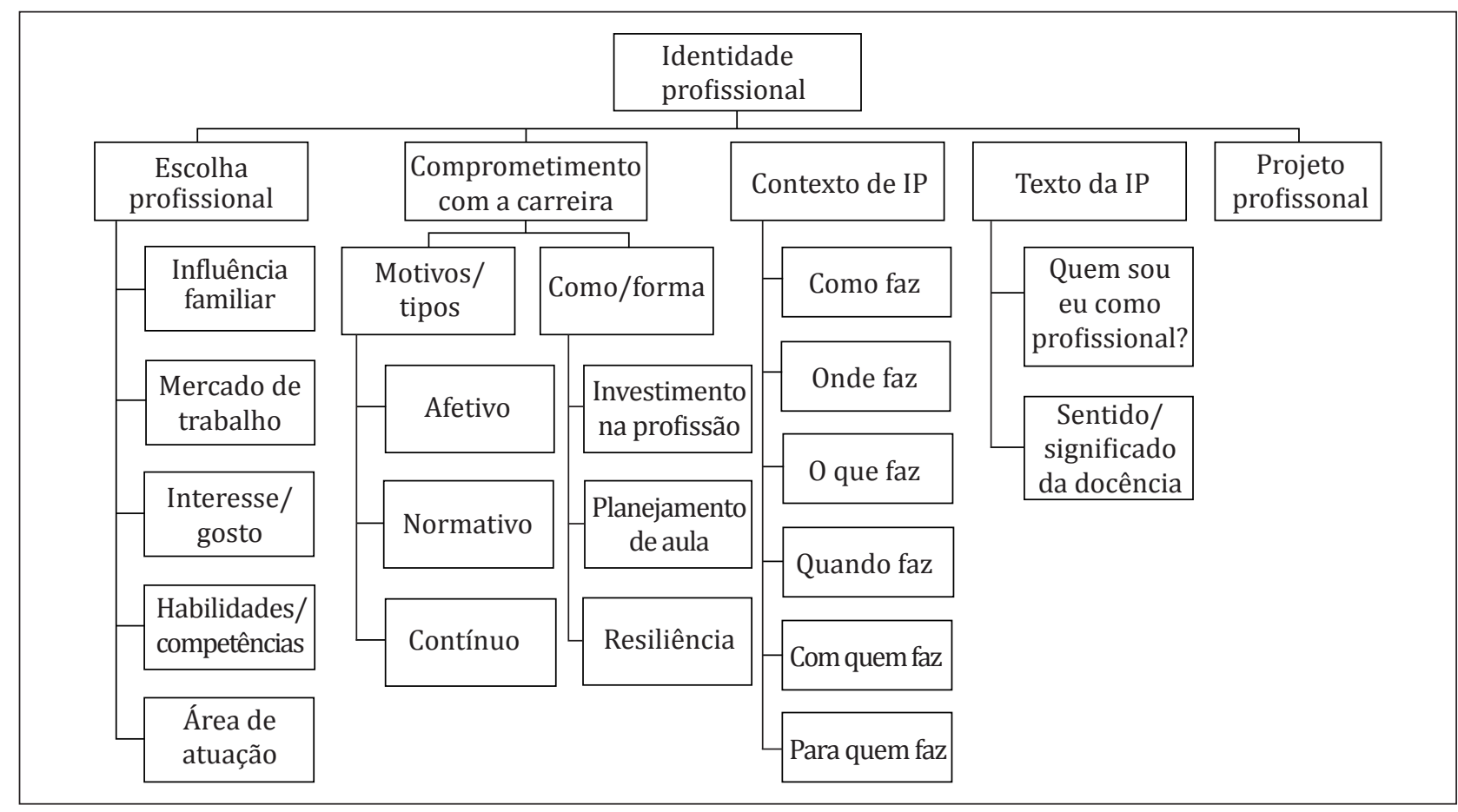

Figura 1 - Categorização identidade profissional Fonte: Dados da pesquisa, 2010. 
Um dos aspectos que compõem a identidade profissional é a resposta à pergunta: "qual a sua profissão?". Esta resposta integra a categoria Texto da Identidade Profissional, que inclui ainda o sentido e o significado da docência para o professor. Não obstante, a identidade vai além de "seu texto", pois envolve uma série de elementos em seu contínuo processo de construção. Assim sendo, as categorias Escolha Profissional, Comprometimento com a carreira, Contexto da Identidade Profissional e Projeto Profissional buscam abranger os demais aspectos da identidade profissional dos professores investigados.

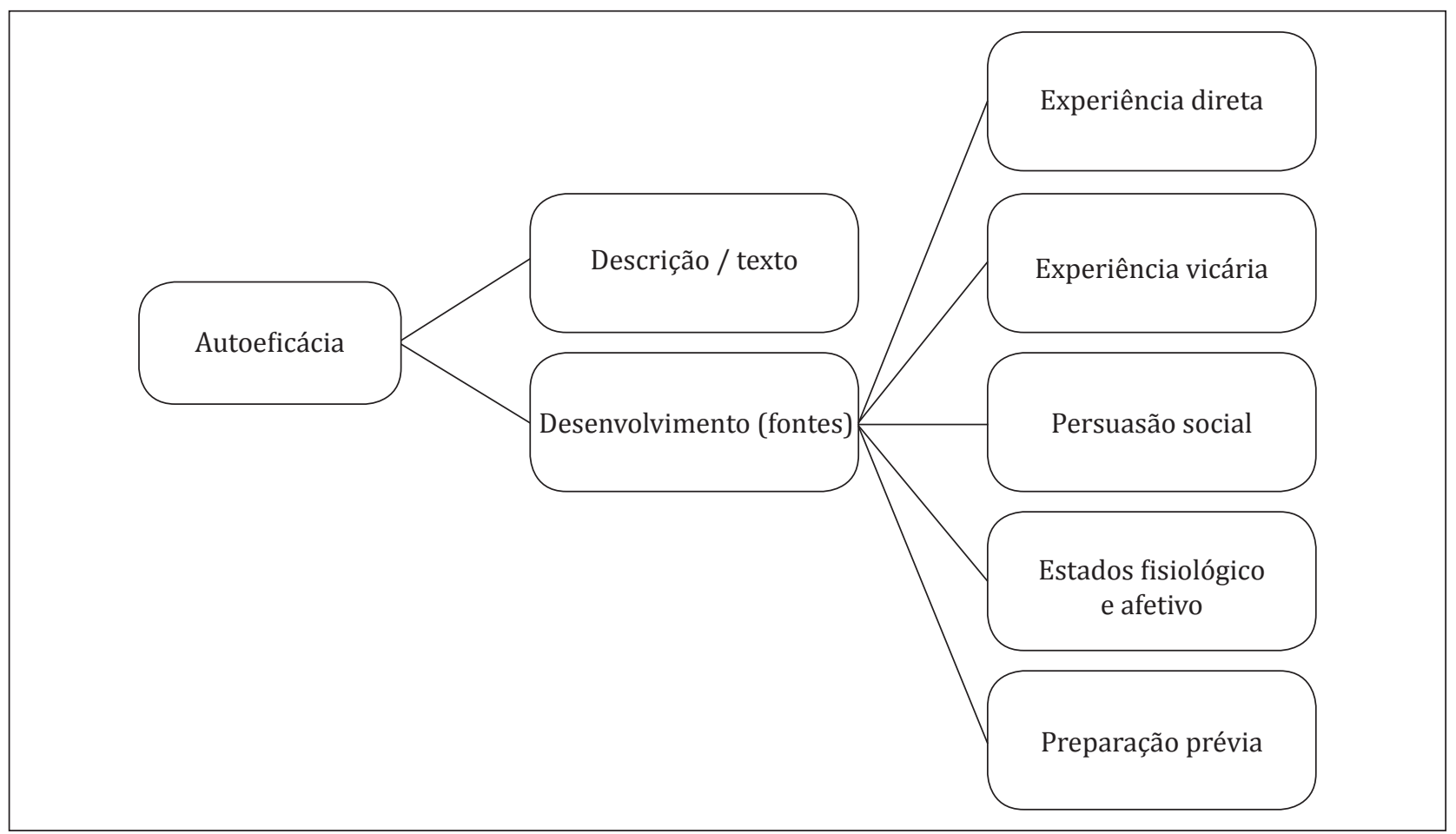

Figura 2 - Categorização autoeficácia

Fonte: Dados da pesquisa, 2010.

O outro conceito, cuja decomposição é representada pela Figura 2, é o de autoeficácia. A categoria Descrição/Texto contempla tanto os resultados da Escala de Autoeficácia Docente, como o conteúdo apresentado pelo professor na entrevista sobre sua capacidade para ensinar. A categoria Desenvolvimento diz respeito às fontes de desenvolvimento das crenças de autoeficácia. Ressaltase que, além das quatro fontes principais apresentadas por Bandura (1994), foi acrescentada uma fonte denominada Preparação prévia, em razão dos motivos apontados pelos professores pesquisados. Observa-se que Preparação prévia é entendida como fonte de desenvolvimento da crença de autoeficácia docente graças à interpretação dos professores acerca de determinados acontecimentos (como a realização de cursos, por exemplo), e não pelos acontecimentos em si.
Ao fim da análise por participante, onde os resultados quantitativos fornecidos pela Escala de Autoeficácia Docente foram cotejados com os conteúdos qualitativos oriundos das entrevistas, foi realizado um estudo global de todos os professores por meio da análise dos conteúdos que apareceram com significativa frequência.

\section{Apresentação e discussão dos resultados}

Como explicitado no método, a escala de autoeficácia foi aplicada em todos os professores das duas escolas com o objetivo de seleção dos participantes da pesquisa.

Na escola pública, a média da crença de autoeficácia dos 27 professores investigados foi 3,40 , sendo que 20 professores apresentaram crença de autoeficácia 
acima de 3,0. Observa-se que dos sete professores com crenças de autoeficácia abaixo de 3,0, cinco são mulheres. Diante disto, foram selecionados quatro professores: as duas professoras que obtiveram as crenças mais baixas de autoeficácia $(2,08$ e 2,17) e os dois professores que apresentaram as crenças de autoeficácia mais elevadas $(4,50$ e 4,67).

Em relação à escola particular, o resultado médio da crença de autoeficácia dos professores, 3,73, apresentou-se um pouco mais alto do que o identificado junto aos professores da escola pública. Observa-se que apenas uma professora dessa escola obteve resultado menor que 3,0. Destarte, selecionaram-se os dois professores com crenças mais baixas de autoeficácia $(2,67$ e 3,17) e os professores com crenças de autoeficácia mais elevadas $(4,58$ e 4,08).

\section{Professores da escola pública}

Mediante os resultados da Escala de Autoeficácia Docente, os professores da escola pública selecionados são apresentados na Tabela 1.

Tabela 1 - Caracterização dos professores da escola pública

\begin{tabular}{cccccc}
\hline $\begin{array}{c}\text { Nome } \\
\text { fictício }\end{array}$ & $\begin{array}{c}\text { Matéria } \\
\text { que } \\
\text { leciona }\end{array}$ & $\begin{array}{c}\text { Idade } \\
\text { em } \\
\text { anos }\end{array}$ & Sexo* $^{*}$ & $\begin{array}{c}\text { Tempo } \\
\text { de } \\
\text { docência }\end{array}$ & $\begin{array}{c}\text { Autoe- } \\
\text { ficácia } \\
\text { docente** }\end{array}$ \\
\hline Carla & Física & 35 & $\mathrm{f}$ & 11 anos & 2,08 \\
Isabela & História & 36 & $\mathrm{f}$ & 18 anos & 2,17 \\
Paulo & $\begin{array}{c}\text { Educação } \\
\text { Física }\end{array}$ & 34 & $\mathrm{~m}$ & 5 anos & 4,50 \\
Francisco & Português & 53 & $\mathrm{~m}$ & 6 anos & 4,67 \\
\hline
\end{tabular}

${ }^{*} \mathrm{f}=$ feminino; $\mathrm{m}=$ masculino.

** Resultado obtido por meio da Escala de Autoeficácia Docente de Woolfolk e Hoy, adaptada por Bzuneck e Guimarães (2003). Fonte: Dados da pesquisa.

\section{A professora Carla}

Carla tem 35 anos e atua como professora há 11 anos. Concluiu a graduação em Física em 1999 e a especialização em Interdisciplinariedade em 2006. Leciona aulas de Física na escola atual, há quatro anos, para as primeiras e segundas séries do ensino médio. Atualmente sua jornada de trabalho semanal é de 40 horas/aula. Trabalha apenas na escola estudada, porém já lecionou aulas de Geografia e de Matemática no início da sua carreira. Dos professores da escola pública, Carla foi quem obteve o menor resultado da escala de autoeficácia.

No decorrer da análise da identidade profissional de Carla, identificam-se alguns pontos que se relacionam com a crença de autoeficácia docente. Carla, ao se descrever como uma professora comprometida e dedicada, demonstra que se percebe desta forma também pela avaliação positiva que recebe dos outros significativos em sua vida, como sua família, seus colegas de trabalho e seus alunos. Pode-se inferir que a persuasão social positiva, além de interferir na crença de autoeficácia de Carla, também reforça sua identidade profissional.

Carla, ao responder a pergunta "O que é ser professor para você", expõe o sentido que a profissão docente tem para ela:

É passar o teu conhecimento, compartilhar o teu conhecimento com o aluno e... não sei se... é compartilhar o teu conhecimento com ele. De repente fazer com que ele perceba que ele também tem um conhecimento, não tão grande quanto o teu, mas ele tem um conhecimento que vai aumentar o meu conhecimento.

Embora a pergunta seja sobre professores de maneira geral, ela responde falando dela e demonstrando que se percebe conseguindo ensinar, o que remete ao conceito de experiência direta. Entendese, desta forma, que a fonte de desenvolvimento da autoeficácia experiência direta contribui para o significado do trabalho docente para Carla e, consequentemente, para a sua identidade profissional.

Com relação ao comprometimento com a profissão, elemento significativo para a compreensão da identidade profissional, Carla expressa que investe em cursos relacionados à educação infantil para aprender a trabalhar com crianças. No caso de Carla, as subcategorias investimento na profissão, da categoria comprometimento com a carreira, e preparação prévia, da categoria fontes de desenvolvimento da autoeficácia, estão diretamente relacionadas. 0 investimento que Carla faz na sua profissão demonstra seu engajamento com a mesma, reforça sua identidade profissional e faz com que se sinta mais capaz de ensinar (aumento da crença de autoeficácia).

De maneira geral, observa-se que a relação entre os dois fenômenos investigados acontece de forma circular. Carla se sente capaz de ensinar de forma eficaz, o que faz com que se identifique mais com 
sua profissão, assim como, por identificar-se com sua profissão, se percebe capaz de ensinar.

\section{A professora Isabela}

Isabela é professora de História, tem 36 anos de idade e trabalha como docente há 18 anos. Antes de ser professora trabalhou com comércio, mas, desde que finalizou o magistério no ensino médio, com 18 anos, nunca mais foi para outra área. Isabela realizou duas graduações: de História, em 1997, e de Pedagogia, em 2004. Em 1999 concluiu uma especialização em História Social e, no período da pesquisa, estava cursando mestrado em Educação.

Além de atuar na Educação Básica (Ensino Fundamental e Médio), trabalha ainda com Educação Infantil. Possui carga horária semanal de 50 horas/ aula e se dedica exclusivamente à docência. Trabalha há três anos na escola investigada, com todas as séries do ensino médio.

A relação entre os dois fenômenos estudados pôde ser verificada com clareza no caso de Isabela. Em diversos momentos da entrevista, demonstrou que se identificava mais com a profissão docente por "saber fazer". Por se perceber capaz de ensinar e de realizar as demais atividades de professor, Isabela se identifica fortemente com sua profissão.

A fala a seguir demonstra essa relação entre "saber fazer" e identidade profissional estabelecida por Isabela: "[...] Eu já passei por direção de escola, por secretarias e parece que eu estou desfocada quando eu estou nesses cargos, porque eu não sei fazer aquilo, entendeu? Me sinto aqui... me realizo dando aula [...]". Tendo em vista que uma das principais consequências da crença da autoeficácia é a persistência do indivíduo frente às dificuldades de percurso (Bandura, 1986), a resiliência apresentada por Isabela pode estar relacionada a sua crença de autoeficácia. Dessa forma, a crença de autoeficácia aparece como fator contribuinte para o estabelecimento da identidade profissional de Isabela.

\section{0 professor Paulo}

Paulo tem 34 anos e trabalha como professor há cinco anos. Concluiu o curso de graduação em Educação Física em 2003. É professor de Educação Física da escola estudada há três anos e proprietário de uma academia de musculação. Leciona Educação Física para as três séries do ensino médio e sua jornada de trabalho como professor é de 20 horas/aula por semana.

No que se refere à escolha profissional, Paulo relatou que acredita ser "vocacional", pois se identifica com o esporte desde pequeno:

na verdade... acho que mais vocação, sabe? Me identifiquei com o esporte desde pequeno. Meu professor de educação física me incentivava bastante, me levava para as corridas, eu gostava de fazer corrida rústica. Fui gostando, fui gostando, e aí fui me interessando... aí fiz o cursinho pré-vestibular, daí eu acho que a opção que veio mais assim foi a vocacional mesmo, daí acabei fazendo educação física.

É possível compreender o significado de "vocação" para Paulo como sendo relacionado a seu gosto/interesse pelo esporte, e não no sentido de "predisposição" ou "dom" como muitas vezes é compreendido. Ainda com base na fala de Paulo, é possível identificar a influência que seu professor exerceu em sua escolha profissional.

Bom, eu acho que todo aluno olha o professor como ponto de referência. Tanto é que foi isso que me estimulou, que eu olhei o meu professor de educação física, ele me estimulou. Eu olhava pra ele assim como um líder. E tudo o que ele falava eu tomava consciência $e$ procurava fazer o que era mais certo para mim.

Evidencia-se a identificação de Paulo com seu professor e sua interferência na escolha pelo esporte como profissão. No estudo realizado por Marinho (2008), os professores destacaram o papel de seus "mestres" no processo de construção de suas identidades docentes ("ser docente").

A escolha de Paulo pelo curso de Educação Física possivelmente ocorreu sob influência da relação entre os conceitos de identidade profissional e autoeficácia. Como discutido anteriormente, Paulo refere-se a sua escolha como sendo "vocacional", baseada em determinados gostos e interesses. A identificação de Paulo com a Educação Física, e seu interesse pela área, relacionam-se com sua percepção a respeito de sua capacidade de desenvolver atividades físicas. A elevada crença de autoeficácia em atividades físicas contribuiu para que Paulo se interessasse pela área, o que, por sua vez, pode ter colaborado com sua identificação com a profissão de professor de Educação Física. Observa-se, nesse 
sentido, que de acordo com a Teoria Sócio-Cognitiva do desenvolvimento de carreira (Lent, Brown e Hackett, 1994), as crenças de autoeficácia e as expectativas de resultados encontram-se envolvidas no processo de formação dos interesses (Nunes, Okino, Noce, \& Jardim-Maran, 2008).

Ao ser questionado sobre o que faz melhor em relação às suas atividades de professor, Paulo responde: "Olha, eu sou muito assim cativante... eu acho que os alunos gostam de mim por causa desse lado de ser muito brincalhão, sempre estar ali com eles... esse lado extrovertido". A resposta de Paulo revela como ele é reconhecido pelos alunos e como se percebe como professor: "muito cativante".

Sugere-se, por meio dos dados explicitados, que a crença de autoeficácia e a identidade profissional de Paulo se relacionam direta e positivamente, em uma relação circular. Novamente observa-se um processo de retroalimentação entre os construtos investigados: Paulo demonstra interesse e se identifica com a profissão por se perceber capaz de exercê-la com eficácia, ao mesmo tempo em que se percebe capaz de ensinar por identificar-se com a profissão docente.

\section{0 professor Francisco}

Francisco tem 53 anos, formou-se em Letras português/espanhol em 2008 e, no momento da pesquisa, iria começar uma pós-graduação em Pedagogia. Atua como professor de Português e de Espanhol há seis anos. Encontra-se na situação de Admitido em Caráter Temporário (ACT) e trabalha em três escolas da rede pública, completando 30 horas/aula semanais, sendo que em uma delas é professor da Educação de Jovens e Adultos (EJA). Na escola em que foi realizada a pesquisa, Francisco leciona, há um mês, aulas de Português para as primeiras e segundas séries do ensino médio. Antes de ser professor, Francisco possuía um comércio próprio.

Dos professores da escola pública estudada, Francisco foi quem apresentou o resultado mais alto na Escala de Autoeficácia Docente $(4,67)$. Essa constatação se confirmou no decorrer de seu discurso, reforçando o resultado da escala. Primeiramente, foi perguntado a Francisco a que ele atribui esse resultado, cuja resposta foi a seguinte:

à minha seriedade. Tudo o que eu faço na vida eu levo a sério. Por simples que seja, eu levo a sério. Ou seja... eu participo de um grupo voluntário, um coral, há 30 anos, eu levo a sério, enquanto eu estou lá eu levo a sério. São ensaios semanais, duas horas por semana, nesse momento eu levo a sério. Então é a seriedade que eu levo em tudo [...].

Essa afirmação remete à compreensão de que, para Francisco, uma das fontes de desenvolvimento do seu senso de autoeficácia é a preparação prévia. Sua fala sobre os ensaios que faz para o coral revela a sua percepção do que significa essa seriedade: o investimento e a dedicação anterior a uma atividade, incluindo a de professor, são considerados como influentes em sua crença de autoeficácia.

No decorrer da entrevista, Francisco demonstrou o que considera ser a função principal do professor: ter conhecimento e transmiti-lo para quem não possui. Para isso, segundo ele, o professor deve assumir uma posição de coordenação, de controle. Francisco considera que possui tais características e que executa bem o papel de coordenador, conforme relatou sobre outras situações profissionais e pessoais (ter um comércio próprio; coordenação de grupos). Nesse sentido, é possível refletir sobre a relação entre sua crença de autoeficácia e sua identidade profissional.

Francisco se identifica com a profissão por sua crença de autoeficácia docente e por perceber a si mesmo como um bom professor. Uma das questões envolvidas no contexto da identidade profissional diz respeito à resposta à pergunta "Como faz?", sendo esta dividida em: "como faz descritivo" e "como faz avaliativo". A primeira refere-se à apresentação da atividade profissional, ao método de ensino; a segunda diz respeito à apreciação do professor acerca de sua atividade profissional. 0 "como faz avaliativo", destarte, relaciona-se à crença de autoeficácia. Neste sentido, o senso de autoeficácia surge como um dos elementos que constituem o contexto da identidade profissional.

Cabe apontar, ainda, uma possível relação entre a idade em que Francisco escolheu ser professor (47 anos), sua elevada crença de autoeficácia e a existência de uma identidade profissional mais consistente. Conforme indica Bzuneck (2000), mudanças de carreira de indivíduos com mais idade envolvem, geralmente, escolhas autênticas e maduras, vinculadas à crença de poder exercer com eficácia as novas tarefas. 


\section{Professores da escola particular}

Dos professores da escola particular que responderam a Escala de Autoeficácia Docente, os quatro professores apresentados na Tabela 2 foram os escolhidos para realizar a entrevista, visto que apresentaram os maiores e os menores valores de crença de autoeficácia docente.

Tabela 2 - Caracterização dos professores da escola pública

\begin{tabular}{cccccc}
\hline $\begin{array}{c}\text { Nome } \\
\text { fictício }\end{array}$ & $\begin{array}{c}\text { Matéria } \\
\text { que } \\
\text { leciona }\end{array}$ & $\begin{array}{c}\text { Idade } \\
\text { em } \\
\text { anos }\end{array}$ & Sexo* & $\begin{array}{c}\text { Tempo } \\
\text { de } \\
\text { docência }\end{array}$ & $\begin{array}{c}\text { Autoe- } \\
\text { ficácia } \\
\text { docente** }\end{array}$ \\
\hline Priscila & Alemão & 45 & f & 20 anos & 2,67 \\
Ronaldo & $\begin{array}{c}\text { Matemá- } \\
\text { tica }\end{array}$ & 40 & m & 20 anos & 3,17 \\
Marcelo & $\begin{array}{c}\text { Educação } \\
\text { Física }\end{array}$ & 45 & $\mathrm{~m}$ & 21 anos & 4,08 \\
Lucas & Física & 34 & $\mathrm{~m}$ & 11 anos & 4,58 \\
\hline
\end{tabular}

$* \mathrm{f}=$ feminino; $\mathrm{m}$ = masculino

** Resultado obtido por meio da Escala de Autoeficácia Docente de Woolfolk e Hoy, adaptada por Bzuneck e Guimarães (2003).

Fonte: Dados da pesquisa.

\section{A professora Priscila}

Priscila tem 45 anos e trabalha há 20 anos como professora. Quando concluiu o ensino médio, no qual cursou magistério, ingressou na Faculdade de Letras português/espanhol. Em 1994 concluiu o mestrado em linguística. Priscila trabalhou apenas como professora, para todas as faixas etárias, desde a pré-escola até a universidade. Já trabalhou em escola pública e particular e na Educação Superior. Atualmente é professora de Alemão da escola estudada e de uma escola de idiomas. Trabalha há 15 anos na escola pesquisada. Sua jornada de trabalho é de 22 horas/aula semanais. É professora das primeiras e segundas séries do ensino médio. Dos professores da escola particular estudada, Priscila foi a única que obteve resultado inferior a 3,0 na escala.

A relação entre os dois construtos pôde ser verificada em alguns pontos da entrevista com Priscila. A professora demonstrou como se perceber capaz de ensinar interfere positivamente na sua identificação com a profissão docente. Quando Priscila relatou sua experiência em uma escola pública, onde precisou superar condições precárias em prol do processo de aprendizagem dos alunos, revelou sua percepção de que foi capaz, de que conseguiu superar as dificuldades (experiência direta). Como consequência, desistiu de abandonar sua profissão e percebeu que "valia a pena", o que reforçou sua identidade profissional docente.

Priscila indica que o mais gratificante em seu trabalho é estar em contato com os alunos e saber que irá encontrar pessoas de quem ela gosta e que reconhecem e valorizam seu trabalho. Nesse sentido, observa-se que a persuasão social, o reconhecimento dos outros, contribuiu para que ela se envolva mais com seu trabalho.

Sobre o que ela considera que faz melhor em relação as suas atividades docentes, Priscila afirmou:

eu acho que é procurar esse contato direto com os alunos, ver se ele aprendeu, se ele está satisfeito. E de repente também tentar inovar, na nossa profissão isso é importante, tentar criar coisas novas. [...] Então é uma das habilidades que o professor tem que ter, e eu acho que eu tenho bastante, é tentar dar sempre de uma maneira diferente, porque o grupo é diferente, porque os alunos são diferentes, porque as pessoas são diferentes.

Desse modo, Priscila demonstra que considera possuir as características atribuídas por ela como sendo da profissão docente, ou seja, identifica-se com sua profissão pois se percebe com as características de um professor. Essas características referem-se à capacidade de fazer com que os alunos aprendam mediante métodos inovadores. Assim, na medida em que Priscila se percebe capaz de realizar as atividades relacionadas à profissão de professor (crença de autoeficácia docente), identifica-se mais fortemente com essa profissão.

Os resultados da entrevista sugerem que a resiliência apresentada pela professora relaciona-se com o aumento de sua crença de autoeficácia docente e que a persuasão social - fonte de desenvolvimento da crença de autoeficácia - contribuiu para que Priscila se identificasse mais com a sua profissão. Supõe-se, portanto, que a crença de autoeficácia docente de Priscila reforce sua identidade profissional e vice-versa, em um movimento circular caracterizado pela retroalimentação constante. 


\section{0 professor Ronaldo}

Ronaldo é um homem de 40 anos que desde os 20 anos atua como professor. Formou-se em duas graduações: Engenharia Civil e Matemática. Fez especialização nas duas áreas e pretende, em breve, dar início a seu mestrado na área de Matemática. Atualmente trabalha só com a rede privada de educação, como professor de Matemática do ensino médio. Na escola pesquisada, há 12 anos Ronaldo é professor das primeiras e terceiras séries do ensino médio.

Verificou-se a relação entre os dois conceitos em questão no momento da escolha profissional de Ronaldo, bem como no exercício de sua profissão. Ronaldo relatou como procurou o primeiro trabalho como professor, enquanto cursava a graduação de Matemática:

eu que procurei... porque dentro da universidade eu já fazia monitoria e rendia bastante. Aí eu comecei a ver que a área da pedagogia tinha muita coisa a ver comigo, comunicação... e aí, nesse período, eu comecei a procurar algum lugar para dar aula para ver se era realmente o que eu queria, fazer uma espécie de balão de ensaio e foi isso que aconteceu, fiz e gostei.

Desta forma, a percepção de Ronaldo, por meio da monitoria, de que era capaz de ensinar (experiência direta), despertou seu interesse em ser professor, o que direcionou sua escolha profissional. Observa-se, novamente, a relação entre a crença de autoeficácia e a formação dos interesses (Lent et al., 1994).

No que diz respeito ao momento atual, Ronaldo relatou que atribui sua crença de autoeficácia a gostar do que faz e que não tem preocupação de ficar desempregado, pois, em suas palavras, "eu sei que, se eu sair daqui, eu vou conseguir trabalhar em outros lugares, porque eu gosto de fazer a coisa com prazer, com vontade". Nesse sentido gostar do que faz aumenta a crença de autoeficácia de Ronaldo. Essa relação foi demonstrada no estudo realizado por Iaochite (2007), no qual se verificou correlação positiva entre a autoeficácia e a variável satisfação docente, ou seja, professores que se sentem mais satisfeitos com a docência tendem a apresentar crenças mais altas de autoeficácia.

Diante disto, no caso de Ronaldo, a experiência direta como monitor e a satisfação com o exercício da docência destacam-se como elementos constitutivos de sua crença de autoeficácia, de seu interesse pela carreira e de sua identidade profissional.

\section{0 professor Marcelo}

Marcelo tem 45 anos e atua há 21 anos como docente. É formado em Educação Física e, em 2002, concluiu uma especialização em currículo e prática educativa. No colégio particular investigado, trabalha como professor de Educação Física e treinador de futebol de campo há 19 anos. Encontra-se envolvido, ainda, com uma escola de samba e está iniciando um projeto social sobre oficinas de costura e adereços. Sua carga horária de professor e treinador é de 36 horas/aula semanais. É professor do ensino fundamental e das primeiras séries do ensino médio.

Na Escala de Autoeficácia Docente obteve o segundo valor mais alto do grupo de professores estudados no colégio particular. Esse resultado revela a crença de Marcelo sobre sua capacidade de ensinar:

eu não sei se eu seria prepotente de dizer que retrata aquilo que eu acho, que eu me acho. Mas é por aí... Eu tenho a satisfação de ser professor, eu gosto de ser professor. [...] O mais fácil [no trabalho que executa] é fazer aquilo que eu faço, porque é o que eu sei fazer.

Percebe-se, assim, que Marcelo relaciona sua crença de autoeficácia ao gosto e satisfação no trabalho, o que condiz os resultados da tese de Iaochite (2007). Observa-se, nesse sentido, que a satisfação com a profissão, relacionada ao comprometimento afetivo, configura-se como um dos elementos da identidade profissional. Diante disto, a relação entre a autoeficácia e a identidade profissional de Marcelo, assim como para Ronaldo, parece envolver a satisfação com o exercício da docência, uma vez que atribui a ela (satisfação) o resultado da escala: "Eu me considero um privilegiado de poder estar fazendo aquilo que eu gosto na vida profissional. Você poder aliar o seu lado profissional com aquilo que você sempre gostou de fazer".

A entrevista de Marcelo exprimiu também a relação entre expectativa de resultados e interesse pela atividade, no momento em que o professor indicou a diferença que percebe entre ministrar aulas e treinar o grupo de jogadores de futebol: 
treinamento mexe com uma coisa que é uma grande paixão que eu sempre tive, que é o futebol, uma coisa que eu sempre fui apaixonado. [...] O futebol é uma coisa mais específica, eu trabalho com um grupo pequeno e sei o objetivo que a gente almeja. Enquanto na aula eu estou com um grupo muito grande e, nem sempre, eu sei se os meus objetivos vão ser alcançados ou não, apesar de eu tentar fazer o melhor para que seja. É mais fácil, com certeza, ser técnico-treinador em todos os aspectos, disciplinar, de alcançar exatamente os objetivos e por trabalhar com um grupo bem pequeno. Então é muito mais fácil. Agora gostar... eu acho que passa pela mesma situação.

De acordo com Nunes (2008, p. 30), "as pessoas envolvem-se nas atividades que acreditam ser capazes de executar e nas quais anteveem resultados positivos". Nesse sentido, Marcelo parece demonstrar um interesse mais intenso na atividade de treinador, pois acredita ser capaz de realizar essa atividade (organizar e executar certo curso de ação) e alcançar resultados positivos. Destaca-se, assim, que além da autoeficácia, as expectativas de resultados, por se encontrarem envolvidas na formação dos interesses, constituem-se como um elemento importante no processo de construção da identidade profissional.

\section{0 professor Lucas}

Lucas tem 34 anos e trabalha como docente há 11 anos. Concluiu a graduação em Engenharia Mecânica em 2000 e o mestrado, na mesma área, em 2003. É professor de Física e possui uma jornada de trabalho que totaliza 45 horas/aula semanais. Além da escola investigada, atua no ensino médio em outra escola privada da região. Na escola estudada trabalha há sete anos, lecionando para alunos das terceiras séries do ensino médio.

Dos professores investigados da escola particular, Lucas apresentou a maior crença de autoeficácia. Ao longo da entrevista, evidenciou que para ser professor é necessário "saber fazer". Este "saber fazer" relaciona-se à sua crença de autoeficácia, uma vez que ele afirma ser capaz de ensinar.

Outra relação percebida no caso de Lucas refere-se à satisfação docente como variável relacionada à autoeficácia e à identidade profissional. Assim como foi identificada junto aos professores Ronaldo e Marcelo, essa relação foi verificada no discurso de Lucas, quando ele indica os motivos do resultado de sua escala: "eu acho que, primeiro, satisfação com o que eu faço. Gostar do que faz eu acho que é fundamental".

Desta maneira, a situação de Lucas sugere novamente que os construtos estudados encontram-se significativamente associados. 0 elevado senso de autoeficácia ("eu sei fazer") e a satisfação com a profissão docente, relacionada ao comprometimento afetivo, constituem-se como elementos de sua identidade profissional.

\section{Considerações finais}

Por se tratar de um estudo exploratório, predominantemente qualitativo, a investigação realizada proporcionou o desenvolvimento de algumas ideias e hipóteses acerca dos construtos pesquisados. De forma geral, identificou-se relação entre a identidade profissional e a crença de autoeficácia nos oito casos estudados, caracterizada por um movimento circular que se retroalimenta constantemente e inclui a formação dos interesses. Os professores se interessam e se identificam com a profissão por acreditarem ser capazes de organizar e executar as atividades docentes, ao mesmo tempo em que se percebem capazes de ensinar por identificarem-se com a profissão docente. Assim, a crença de autoeficácia pode ser estudada como um dos componentes presentes no processo de construção da identidade profissional.

Observa-se, de modo geral, que os professores investigados, todos com significativo tempo dedicado à profissão docente, apresentaram como principal fonte de desenvolvimento de suas crenças de autoeficácia a experiência direta, o que se encontra em consonância com os resultados de um recente levantamento realizado por Rocha (2009) junto a 457 docentes do ensino superior. Entretanto isso não significa que quanto maior o número de experiências relacionadas à prática docente, maior será crença de autoeficácia, uma vez que essa relação é mediada pela interpretação do sujeito sobre a experiência. Professores com maior tempo de docência e crenças mais baixas de autoeficácia, possivelmente, não avaliam parte de suas experiências pessoais na área profissional como bem sucedida. 
Tendo em vista as discussões apresentadas, alguns aspectos devem ser explorados mediante outros estudos. A escala de autoeficácia docente utilizada nesta investigação mensura, além da eficácia pessoal (que foi pesquisada), a eficácia coletiva. Por não ser o objetivo deste trabalho, esta última não foi discutida. Não obstante, os resultados obtidos na entrevista e na escala, bem como a literatura na área, indicam a importância da eficácia coletiva na prática docente, o que pode se relacionar com a identidade profissional dos professores de uma forma mais abrangente.

Como é possível observar na discussão dos casos, os resultados obtidos por meio da Escala de Autoeficácia Docente divergiram, em algumas situações, dos discursos apresentados pelos professores nas entrevistas. Esse fato denota a necessidade de se cotejar e associar métodos quantitativos e qualitativos de pesquisa, uma vez que os números podem ser insuficientes para revelar com mais precisão e aprofundamento os significados que os indivíduos atribuem aos fenômenos estudados.

Em razão da complexidade envolvida no processo de ensino e aprendizagem, destaca-se a relevância de estudos sobre autoeficácia de professores para a compreensão das motivações, dos comportamentos (Bzuneck, 1996) e da identidade desses profissionais. 0 professor encontra em seu cotidiano profissional diferentes obstáculos, fracassos e frustrações relacionados aos próprios alunos, às limitações e falhas da organização escolar e do sistema educacional de forma ampla. Nesse cenário, o senso de autoeficácia se torna um fator importante que pode motivar o professor a ser criativo e persistente em seu objetivo de ensinar (Bandura, 1993) e menos vulnerável ao estresse (Pocinho \& Capelo, 2009), mesmo frente às dificuldades encontradas em seu trabalho, o que se relaciona com a manutenção de um sentido de identidade profissional.

Desta forma, estudos sobre o desenvolvimento das crenças de autoeficácia de docentes, associados ao processo de construção da identidade profissional, proporcionam subsídios para intervenções com professores e instituições escolares, sobretudo no que se refere ao enfrentamento dos obstáculos encontrados, à persistência na profissão, e seus reflexos na qualidade do ensino oferecido, mediante a aprendizagem e a motivação dos alunos.

\section{Referências}

Alves-Mazzotti, A. J. (2002). A "revisão da bibliografia" em teses e dissertações: Meus tipos inesquecíveis - o retorno. In L. Bianchetti \& A. M. N. Machado (Org.). A bússola do escrever: Desafios e estratégias na orientação de teses e dissertações (pp. 25-41). Florianópolis: Ed. da UFSC; São Paulo: Cortez.

Baiocchi, A. C., \& Magalhães, M. (2004). Relações entre processos de comprometimento, entrincheiramento e motivação vital em carreiras profissionais. Revista Brasileira de Orientação Profissional, 5(1), 63-69.

Bandura, A. (1977). Self-efficacy: Toward a unifying theory of behavioral change. Psychological Review, 84(2), 191-215.

Bandura, A. (1986). Social foundations of thought and action: A social cognitive theory. Englewood Cliffs, NJ: Prentice Hall.

Bandura, A. (1993). Perceived self-efficacy in cognitive development and functioning. Educational Psychologist, 28(2), 117-148.

Bandura, A. (1994). Self-efficacy. In V. S. Ramachaudran. Encyclopedia of human behavior. (Vol. 4, pp. 71-81). New York: Academic Press.

Bragagnolo, R. I., \& Luna, I. N. (2004). Educação e novas exigências profissionais: Novas exigências à prática docente e constituição da identidade profissional de educadores de $1^{\underline{a}}$ à $4^{\text {a }}$ série. Anais do 27ํㅡㄹ Reunião Anual da ANPEd, Textos de Trabalhos e Pôsteres, Caxambu. Recuperado em 26 mar. 2011, em http:// www.anped.org.br/reunioes/27/inicio.htm

Brando, F. R., \& Caldeira, A. M. A. (2009). Investigação sobre a identidade profissional em alunos de licenciatura em ciências biológicas. Ciência e Educação, 15(1), 155-173.

Brasil. Lei n. 9.394/96, de 20 de dezembro de 1996. Estabelece as diretrizes e bases da educação nacional. Diário Oficial [da] República Federativa do Brasil, Poder Legislativo, Brasília, DF, 23 dez. 1996. p. 27833. Recuperado em 23 jul. 2011. http:// www6.senado.gov.br/legislacao/ListaTextoIntegral. action?id=75723 
Brophy, J. (1991). Introduction. In J. Brophy (Ed.) Advances in Research on Teaching (Vol. 2, pp. 9-15). Greenwich: JAI Press.

Bzuneck, J. A. (1996). Crenças de autoeficácia de professoras de $1^{\circ}$ grau e sua relação com outras variáveis de predição e de contexto. Arquivos Brasileiros de Psicologia, 48(4), 57-89.

Bzuneck, J. A. (2000). As crenças de autoeficácia dos professores. In F. F. Sisto, G. C. Oliveira \& L. D. T. Fini (Org.). Leituras de psicologia para formação de professores (pp.115-152). Petrópolis: Vozes.

Bzuneck, J. A., \& Guimarães, S. E. R. (2003). Crenças de eficácia de professores: Validação da escala de Woolfolk e Hoy. Psico-USF, 8(2), 137-143.

Caregnato, R. C. A., \& Mutti, R. (2006). Pesquisa qualitativa: Análise do discurso versus análise de conteúdo. Texto Contexto Enferm, 15(4), 679-684.

Ciampa, A. C. (1987). A estória do Severino e a estória da Severina: Um ensaio de psicologia social. São Paulo: Brasiliense.

Ciampa, A. C. (2007). Identidade. In S. T. M. Lane \& W. Codo (Org.). Psicologia social: 0 homem em movimento (pp. 58-75). São Paulo: Brasiliense.

Costa, J. F. (1989). Psicanálise e contexto cultural: Imaginário psicanalítico, grupos e psicoterapia. Rio de Janeiro: Campus.

Coutinho, M. C. (1999). Trabalho e construção da identidade. Psicologia em Estudo, 4(1), 29-43.

Coutinho, M. C., Krawulski, E., \& Soares, D. H. P. (2007). Identidade e trabalho na contemporaneidade: repensando articulações possíveis. Psicologia e Sociedade, 19(Supl. 1), 29-37.

Dubar, C. (1998). Trajetórias sociais e formas identitárias: Alguns esclarecimentos conceituais e metodológicos. Educação e Sociedade, 19(62), 13-30.

Erikson, E. (1976). Identidade, juventude e crise. Rio de Janeiro: J. Zahar.

Freitas, F. L. (2006). A constituição da identidade docente: Discutindo a prática no processo de formação. Dissertação de Mestrado, Universidade Estadual de Campinas, Campinas.
Fundação Getúlio Vargas. (2009). 0 tempo de permanência na escola e as motivações dos sem-escola. Rio de Janeiro: FGV; IBRE; CPS.

Galindo, W. C. M. (2004). A Construção da identidade profissional docente. Psicologia: Ciência e Profissão, 24(2), 14-23. Recuperado em 25 mar. 2009, em http://pepsic.bvs-psi.org.br/scielo.php?script=sci_ arttext\&pid=S1414-98932004000200003\&lng=pt\& nrm=iso.

Gil, A. C. (1999). Métodos e técnicas de pesquisa social (5a ed). São Paulo: Atlas.

González Rey, F. L. (2002). Pesquisa qualitativa em psicologia: Caminhos e desafios (2a ed). São Paulo: Pioneira Thomson Learning.

Guareschi, N. M. F., Medeiros, P. F., \& Bruschi, M. E. (2003). Psicologia social e estudos culturais: Rompendo fronteiras na produção do conhecimento. In N. M. F. Guareschi \& M. E. Bruschi (Ed.). Psicologia Social nos estudos culturais: Perspectivas e desafios para uma nova Psicologia Social (pp. 23-49). Petrópolis: Vozes.

Hall, S. (2001). A identidade cultural na pós-modernidade. Rio de Janeiro: DP\&A.

Iaochite, R. T. (2007). Auto-eficácia de docentes de educação física. Tese de Doutorado não publicada, Universidade Estadual de Campinas, Campinas.

Jacques, M. G. C. (1996). Identidade e trabalho: Uma articulação indispensável. In A. Tamaio, J. E. BorgesAndrade \& W. Codo (Ed.). Trabalho, organizações e cultura (pp. 41-47). São Paulo: Cooperativa dos Autores Associados.

Lent, R., Brown, S. D., \& Hackett, G. (1994). Toward a unifying social cognitive theory of career and academic interest, choice and performance. Journal of Vocational Behavior, 45, 79-122.

Lüdke, M., \& André, M. E. D. A. (1986). Pesquisa em educação: Abordagens qualitativas. São Paulo: EPU.

Luna, I. N., \& Baptista, L. C. (2001). Identidade profissional: Prazer e sofrimento no mundo do trabalho. Psicologia Revista, 12(1), 39-51. 
Castelo, L. B., \& Luna I. N.

Marinho, A. P. A. (2008). Do ser professor das séries iniciais: Marcas identitárias na atuação profissional. Dissertação de Mestrado em Educação, Universidade Federal do Rio de Janeiro, Rio de Janeiro.

Martin-Baró, I. (1985). Acción e ideologia: Psicologia social desde Centroamérica. San Salvador, El Salvador: UCA.

Nunes, M. F. O., Okino, E. T. K., Noce, M. A., \& Jardim-Maran, M. L. C. (2008). Interesses profissionais: Perspectivas teóricas e instrumentos de avaliação. Avaliação Psicológica, 7(3), 403-414.

Nunes, M. F. O. (2008). Funcionamento e desenvolvimento das crenças de autoeficácia: Uma revisão. Revista Brasileira de Orientação Profissional, 9(1), 29-42.

Oliveira, D. A. (2004). A reestruturação do trabalho docente: Precarização e flexibilização. Educação e Sociedade, 25(89). Recuperado em 25 mar. 2009, em http://www.scielo.br/pdf/es/v25n89/22614.pdf

Pajares, F., \& Olaz, F. (2008). Teoria social cognitiva e autoeficácia: Uma visão geral. In A. Bandura, R. G. Azzi \& S. Polydoro, Teoria Social Cognitiva: Conceitos básicos (pp. 97-114). Porto Alegre: Artmed.

Pocinho, M., \& Capelo, M. R. (2009). Vulnerabilidade ao stress, estratégias de coping e autoeficácia em professores portugueses. Educação e Pesquisa, 35(2), 351-367.
Rocha, M. S. (2009). A auto eficácia docente no ensino superior. Tese de Doutorado em Educação, Universidade Estadual de Campinas, Campinas.

Sader, E. (1988). Quando novos personagens entraram em cena: Experiências, fatos e lutas dos trabalhadores na grande São Paulo em 1970-80. Rio de Janeiro: Paz e Terra.

Santos, M. F., \& Santos, E. A. (1993). Identidade e trabalho: Um estudo de caso. Estudos de Psicologia, 10(2), 57-72.

Silva, T. T. (2004). A produção social da identidade e da diferença. In Silva, T. T. (Ed.). Identidade e diferença: A perspectiva dos estudos culturais (pp. 73-102). Petrópolis: Vozes.

Souza, L. F. N. I. (2010). Estratégias de aprendizagem e fatores motivacionais relacionados. Educar em Revista, 36, 95-107.

Woodward, K. (2004). Identidade e diferença: Uma introdução teórica e conceitual. In Silva, T. T. (Ed.). Identidade e diferença: A perspectiva dos estudos culturais (pp. 7-72). Petrópolis: Vozes. 